\title{
PRÁTICAS DE ENFERMEIROS E A INFLUÊNCIA SOCIOCULTURAL NA ADESÃO AO ALEITAMENTO MATERNO
}

\section{NURSING PRACTICES AND THE SOCIOCULTURAL INFLUENCE ON BREASTFEEDING ADHERENCE}

\section{LAS PRÁCTICAS DE ENFERMERÍA Y LA INFLUENCIA SOCIOCULTURAL EN LA ADHESIÓN A LA LACTANCIA MATERNA}

\author{
Giovana Callegaro Higashi ${ }^{1}$ \\ Sibeli Seefeld dos Santos ${ }^{2}$ \\ Rosielle Souza da Silva ${ }^{3}$ \\ Leonardo Bigolin Jantsch ${ }^{4}$ \\ Rafael Marcelo Soder ${ }^{5}$ \\ Luiz Anildo Anacleto da Silva ${ }^{6}$
}

\begin{abstract}
Como citar este artigo: Higashi GC, Santos SS, Silva RS, Jantsch LB, Soder RM, Silva LAA. Práticas de enfermeiros e a influência sociocultural na adesão ao aleitamento materno. Rev baiana enferm. 2021;35:e38540.

Objetivo: descrever as práticas de enfermeiros da atenção primária em saúde e a influência sociocultural na adesão ao aleitamento materno. Método: estudo qualitativo à luz da Teoria Fundamentada nos Dados, segundo o modelo construtivista de Charmaz. Participaram dez puérperas e nove enfermeiros vinculados à Equipe de Saúde da Família de um município localizado na região noroeste do Rio Grande do Sul. Os dados foram coletados por entrevista semiestruturada, no período de março a julho de 2019. Resultados: emergiu uma categoria intitulada "Promovendo o aleitamento materno e as implicações socioculturais na pratica da amamentação”, e duas subcategorias: Práticas de enfermeiros durante o gravídico-puerpural e a influência sociocultural na adesão ao aleitamento materno; Práticas obstétricas e pediátricas e os desafios no puerpério (imediato e mediato). Conclusão: os enfermeiros apontaram inúmeras práticas para o fortalecimento e a adesão ao aleitamento materno desde o pré-natal ao puerpério, reconhecendo os desafios socioculturais impostos.
\end{abstract}

Descritores: Aleitamento Materno. Enfermagem. Saúde Materno-Infantil.

Objective: to describe the practices of primary bealth care nurses and the socio-cultural influence on breastfeeding adherence. Method: qualitative study in the light of Grounded Theory, according to the constructivist model of

\footnotetext{
Enfermeira. Doutora em Enfermagem. Professora Adjunta do Departamento de Enfermagem da Universidade Federal da Bahia. Palmeira das Missões, Rio Grande do Sul, Brasil. gio.enfermagem@gmail.com. http://orcid.org/0000-0002-5171-1529.

2 Enfermeira. Enfermeira assistencial do Hospital de Caridade de Palmeira das Missões. Palmeira das Missões, Rio Grande do Sul, Brasil. http://orcid.org/0000-0002$|406-480|$

3 Estudante de Enfermagem. Universidade Federal de Santa Maria. Santa Maria, Rio Grande do Sul, Brasil. http://orcid.org/0000-000 I-8787-6627.

Enfermeiro. Doutor em Enfermagem. Professor Adjunto do Departamento de Enfermagem da Universidade Federal de Santa Maria. Palmeira das Missões, Rio Grande Sul, Brasil. http://orcid.org/0000-0002-457|- I83X.

Enfermeiro. Doutor em Enfermagem. Professor Adjunto do Departamento de Enfermagem da Universidade Federal de Santa Maria. Palmeira das Missões, Rio Grande do Sul, Brasil. http://orcid.org/0000-0003-4467-1933.

6 Enfermeiro. Doutor em Enfermagem. Professor Adjunto do Departamento de Enfermagem da Universidade Federal de Santa Maria. Palmeira das Missões, Rio Grande do Sul, Brasil. http://orcid.org/0000-0003-065।-7804.
} 
Charmaz. Ten puerperal women and nine nurses associated with the Family Health Team of a municipality located in the northwest region of Rio Grande do Sul participated. The data were collected by semi-structured interview, from March to July 2019. Results: a category entitled "Promoting breastfeeding and the sociocultural implications of breastfeeding" emerged, and two subcategories: Nurses' practices during the pregnant and puerpural period and the sociocultural influence on breastfeeding adherence; Obstetrics and paediatric practices and the challenges in the puerperium (immediate and intermediate). Conclusion: the nurses pointed out numerous practices for the strengthening and the adherence to breastfeeding from prenatal to puerperium, recognizing the sociocultural challenges imposed.

\section{Descriptors: Breastfeeding. Nursing. Maternal and Child Health.}

Objetivo: describir las prácticas de la enfermería de atención primaria y la influencia sociocultural en la adhesión a la lactancia materna. Método: estudio cualitativo a la luz de la Teorización Anclada, según el modelo constructivista de Charmaz. Participaron diez mujeres en el puerperio y nueve enfermeros asociados al Equipo de Salud Familiar de un municipio situado en la región noroccidental de Río Grande do Sul. Los datos se recogieron mediante una entrevista semiestructurada, de marzo a julio de 2019. Resultados: ha surgido una categoría titulada "Promoviendo la lactancia materna y las implicaciones socioculturales del amamantamiento" y dos subcategorías: Prácticas de enfermería durante el embarazo y el puerperio y la influencia sociocultural en la adhesión a la lactancia materna; Las prácticas de obstetricia y pediatría y los desafios en el puerperio (inmediato e intermedio). Conclusión: los enfermeros señalaron numerosas prácticas de fortalecimiento y adhesión a la lactancia materna desde el periodo prenatal hasta el puerperio, reconociendo los retos socioculturales que se imponen.

Descriptores: Lactancia materna. Enfermería. Salud materna e infantil.

\section{Introdução}

Nas últimas décadas, diversos programas e políticas de promoção, proteção e apoio ao aleitamento materno (AM) foram implementadas com o propósito de fortalecer esta prática e propor novas estratégias para maior conscientização e melhora dos indicadores de saúde materno-infantil $^{(1)}$. Os índices de AM apresentaram melhora significativa nas últimas décadas no Brasil, contribuindo para a redução de taxas de mortalidade. Entretanto, ainda vivenciamos baixos índices de adesão, especialmente ao aleitamento materno exclusivo, recomendando pela Organização Mundial de Saúde (OMS). Nos países de baixa e média renda, como o Brasil, apenas 37\% das crianças com menos de 6 meses de idade são amamentadas de forma exclusiva ${ }^{(2)}$.

As intervenções realizadas pelo enfermeiro no âmbito da atenção primária de saúde (APS) buscam promover, proteger e assegurar que o ciclo gravídico da mulher transcorra com o máximo de segurança e qualidade, identificando precocemente as alterações e reduzindo os riscos e complicações que por ventura possam surgir. Nesse sentido, especialmente durante o pré-natal, este profissional desenvolve suas ações para orientar, informar e conscientizar acerca dos benefícios da amamentação tanto para o lactente quanto para a mãe, para que, após o nascimento, o aleitamento materno ocorra com naturalidade, e mesmo diante de alguma dificuldade, esta possa ser superada juntamente com uma rede de apoio fortalecida e com o suporte de uma equipe multiprofissional ${ }^{(3-5)}$.

Comumente, diversos são os entraves enfrentados pelas puérperas para poderem amamentar, dentre eles as dificuldades fisiopatológicas, como o ingurgitamento, a mastite, o bloqueio de ductos lactíferos, o trauma mamilar, abcesso mamário, infecção etc. Como consequência destas condições, acaba ocorrendo a desistência da oferta do leite materno, seguido do início precoce de fórmulas e leites industrializados, muitas vezes, sob a influência de profissionais de saúde e familiares, imbuídos em suas práticas socioculturais. Desse modo, cabe destacar que é no contexto da APS que são realizadas grande parte das consultas de pré-natal e puerpério, principalmente por meio das práticas desenvolvidas pelos enfermeiros, tornando-se, assim, um serviço importante e necessário para a promoção, proteção 
e promoção de ações de educação em saúde em prol do aleitamento materno ${ }^{(6)}$. Nesse contexto, o enfermeiro é o profissional capacitado para oferecer à mulher subsídios teóricos e práticos em prol da amamentação por meio de relações dialógicas, empáticas, valorizando a individualidade, a autonomia e enfatizando a importância do protagonismo da mulher em todo o processo gravídico-puerperal.

Nessa perspectiva, com base nos saberes e práticas dos enfermeiros da APS em seus cotidianos de cuidados na atenção ao pré-natal e puerpério, sob a perspectiva da amamentação, o estudo tem por objetivo descrever as práticas de enfermeiros da APS e a influência sociocultural na adesão ao aleitamento materno.

\section{Método}

Trata-se de estudo qualitativo, descritivo e exploratório que utilizou a Teoria Fundamentada nos Dados (TFD) como filiação metodológica, segundo o modelo teórico construtivista de Charmaz, de 2009. Os procedimentos associados à metodologia possibilitam conduzir, controlar e organizar a coleta de dados com base na compreensão dos dados sob uma perspectiva inovadora, explorando as ideias por meio de uma redação analítica ${ }^{(7)}$.

A amostragem teórica foi composta por 19 participantes, incluindo enfermeiros e puérperas vinculadas à Equipe de Saúde da Família (ESF) de um município localizado na região noroeste do Rio Grande do Sul, totalizando 10 ESF. Desse modo, o primeiro grupo amostral contou com dez puérperas (uma de cada ESF), e o segundo grupo amostral, com nove enfermeiros (um de cada serviço da APS do município); cabe destacar que um enfermeiro não aceitou participar do estudo.

Com base na hipótese gerada pelo primeiro grupo amostral (puérperas), identificou-se que as puérperas enfrentavam diversos desafios para amamentar e, por sua vez, estabeleciam contato com os enfermeiros por meio das consultas de enfermagem balizadas por momentos de diálogo, orientação e troca de informação. Dessa forma, os enfermeiros foram incluídos para participar do estudo e compuseram o segundo grupo amostral. Este artigo é um recorte de um estudo maior intitulado "Desafios e potencialidades encontradas pelas puérperas ao amamentar". Devido a importância da atuação do enfermeiro para o empoderamento das puérperas que amamentam, por meio do acompanhamento, das práticas de educação em saúde, das orientações e intervenções tanto no pré-natal quanto na fase do puerpério, optou-se por descrever os saberes e práticas de enfermeiros na adesão ao AM.

O critério de inclusão foi possuir experiência nas ESF de, no mínimo, dois anos. O critério de exclusão foi apresentar período inferior a dois anos nas atividades laborais na ESF do município. Os dados foram coletados nos meses de março a julho de 2019, e a escolha pelos profissionais de saúde deu-se de forma intencional. O local e a hora da entrevista foram definidos via contato telefônico e o agendamento nas unidades, conforme a disponibilidade. As entrevistas foram conduzidas por uma acadêmica de enfermagem e pela pesquisadora responsável do estudo. Para a coleta de dados utilizou-se a entrevista semiestruturada com perguntas abertas e fechadas em uma sala cedida pela ESF, utilizando-se do recurso de gravação digital para o registro das falas (com o tempo médio das entrevistas de 20 minutos), e armazenadas em Word. Cita-se, dentre outras, uma das perguntas que guiou a entrevista: Descreva quais são as práticas de enfermeiros no contexto da amamentação e como são desenvolvidas.

A análise dos dados foi guiada pelo questionamento constante do pesquisador para captar os significados dos dados da pesquisa. Codificar significa analisar e categorizar achados com uma denominação sintética que resume e reúne cada parte dos dados. Os códigos emergem da análise minuciosa dos dados e a codificação na TFD promove o estudo da ação e dos processos entre os indivíduos pesquisados ${ }^{(7)}$. A saturação dos dados ocorreu quando da repetição dos achados explanados pelos participantes do estudo.

Os critérios éticos de pesquisas envolvendo seres humanos foram observados e atendidas as 
recomendações da Resolução n. 466/2012 do Conselho Nacional de Saúde (CNS), sob o CAA: 05841218.1.0000.5346. Dessa forma, assegurou-se o sigilo e a privacidade da identidade dos participantes, o anonimato e a confidencialidade das informações, bem como os princípios de autonomia, beneficência, não maleficência, justiça e equidade. $\mathrm{O}$ anonimato dos participantes foi mantido com a substituição do nome por GA2 (grupo amostral 2), seguido pela letra $\mathrm{P}$ de participante e de números que corresponderam à sequência das entrevistas (P1, P2, P3...).

\section{Resultados}

Após a análise dos dados emergiu uma categoria intitulada "Promovendo o aleitamento materno e as implicações socioculturais na pratica da amamentação", seguida por duas subcategorias: Práticas de enfermeiros durante o gravídico-puerpural e a influência sociocultural na adesão ao aleitamento materno; e Práticas obstétricas e pediátricas e os desafios no puerpério (imediato e mediato).

\section{Promovendo o aleitamento materno e as implicações socioculturais na pratica da amamentação}

É notório a importância da participação do profissional de saúde durante o período gestacional, buscando solucionar dúvidas e dificuldades que possam emergir durante o processo. Uma gestante empoderada com informações robustas sobre o aleitamento materno pode mitigar a desistência e reduzir a tomada de decisão sob a influência sociocultural para a não adesão a esta prática. A seguir, será apresentada a primeira subcategoria encontrada no estudo.

\section{Práticas de enfermeiros durante o gravídico-puerperal e a influência sociocultural na adesão ao aleitamento materno}

O processo de amamentação da mulher engloba aspectos subjetivos e objetivos que incluem desde o preparo físico, emocional até a compreensão e o incentivo por parte dos familiares e o acompanhamento por parte dos profissionais de saúde. Logo, são inúmeros os desafios e as dificuldades enfrentadas pelas gestantes durante o ciclo gravídico puerperal, como é possível perceber no enunciado a seguir:

Porque o processo de amamentação não é tão lindo como a gente pinta! Sim, é uma coisa maravilhosa se a puérpera conseguir êxito, mas claro, vai ter que acordar de madrugada, nos primeiros dias não desce muito leite, depois que desce o leite, tende a ter o ingurgitamento mamário e você trata o ingurgitamento, depois esgota, você orienta que tem que continuar dando o seio, dai vem as fissuras. (GA2P7).

As práticas desenvolvidas pelos enfermeiros no contexto da APS se referem às orientações durante o pré-natal, à assistência clínica frente às intercorrências gestacionais e à construção de vínculo, dentre outras. Desse modo, os enfermeiros que participaram do estudo ressaltaram a necessidade de desmistificar os conhecimentos culturais que a mulher carrega, muitas vezes, sob a influência dos familiares, os quais podem interferir no processo de amamentação.

\begin{abstract}
As orientações sobre amamentação desde o início do pré-natal são importantes, porque ao longo do pré-natal você vai desmistificando tudo que ela sabe sobre a questão cultural de amamentação, sobre as possiveis intercorrências que possam vir a ter e sobre a importância da amamentação para o bebê. Então, a gente vai criando vinculo durante o pré-natal e a gente já iniciando a conversa precocemente a amamentação tem mais sucesso. (GA2P5).
\end{abstract}

Especialmente as mães de primeira viagem, elas têm muita imaturidade, e aceitam muita opinião de vó, de tia, que dizem que o leite é fraco, que o bebê só fica chorando. (GA2P4).

Corroborando esses depoimentos, alguns profissionais reforçaram a importância de estabelecer práticas que promovam a construção de vínculo, pois torna-se possível iniciar de forma precoce a troca de informações e orientações. Assim, ao defrontar-se com alguma dificuldade no período da amamentação, as puérperas encontram maior abertura e segurança para procurar a ESF na busca de ajuda e solução para tal problema, o que propicia menor chance de abandonar a amamentação no momento de fragilidade. Outra prática que deve ser favorecida refere-se à inclusão de acompanhantes, como 
os pais ou avós, nas consultas pré-natal, pois a sua presença e apoio são fundamentais, principalmente para as gestantes primigestas que irão vivenciar a sua primeira experiência gestacional.

\begin{abstract}
A importância no pré-natal a gente conversar também com o acompanhante, os avós que geralmente acompanham a consulta, com o pai, que é importante para depois ter maior apoio na amamentação que a gente sabe que tem bastante puérpera primigesta que possui maior dificuldade. (GA2P5).
\end{abstract}

No entendimento dos profissionais, pela falta de experiência e preparo, as puérperas têm medo de que o bebê possa estar passando fome devido ao fato do recém-nascido mamar repetidas vezes, mas não a necessidade certa. Atrelado a isso, a presença e a interferência cultural dos familiares reforçam a crença que o leite não é o suficiente para o bebê e/ou questionam a qualidade do leite materno, afirmando que ele é fraco. Destacam a necessidade de introdução de leite industrializado, o que acaba contribuindo para que o bebê reduza o instinto de sugar o seio materno.

\begin{abstract}
É o medo que elas têm, se têm muito medo que o bebê esteja passando fome, porque o recém-nascido mama com uma frequência maior, devido a quantidade de leite que é ingerido durante a mamada, pelo leite ser o colostro, que tem menos quantidade de gordura. Elas têm muito medo de que eles estejam com fome, e como muda muito as informações de uma geração para outra. Às vezes, as avós também interferem negativamente, como quando eu era criança a maioria das crianças eram aleitadas com leite de fórmulas, era mais vendido pela indústria, então tem todos esses entraves. (GA2P3).
\end{abstract}

Uma importante prática de educação em saúde realizada pelo enfermeiro refere-se à criação de grupos de gestantes em prol do seu empoderamento para o AM. Não obstante a importância da criação de grupos, os profissionais, de modo geral, não estão conseguindo realizar os encontros com as mulheres por falta de adesão, justificado por inúmeros motivos, como, por exemplo, algumas trabalham fora e não conseguem liberação (essa ausência é permitida apenas para as consultas por lei), e outras por terem filhos pequenos e, dessa forma, não conseguem sair de casa para os encontros.

Nós tentamos criar por duas vezes [Grupo de Gestantes] e ele não foi efetivo, porque aqui a grande maioria das gestantes trabalba fora, então, quando muito, algumas conseguiam liberação. (GA2P2).
$\mathrm{Na}$ ótica dos enfermeiros, muitas gestantes não consideram importante as participações no grupo, pois acreditam que as consultas são suficientes para sanar as suas dúvidas e a insegurança. Os enfermeiros relataram a tentativa da criação do grupo diversas vezes e de diversas maneiras, por exemplo, trazendo uma equipe multiprofissional como nutricionista, fisioterapeuta, ofertando brindes e kit para as gestantes. Entretanto, mesmo assim, a participação ocorre apenas nos primeiros encontros e, após, acaba-se tendo dificuldades para mantê-lo por falta de participação, não obtendo sucesso.

Elas acham que podem perguntar tudo na consulta e o grupo não é preciso. Mas pela troca de experiência, elas não têm essa visão de grupo. (GA2P2).

Elas não julgam importante! Elas vêm na consulta e acham que é suficiente. (GA2P8).

Então, a nutricionista ia falar sobre alimentação, a fisioterapeuta ia falar sobre parto e exercícios na gestação para os trabalbos de parto, nós tínhamos um cronograma que, no nosso ver, era ótimo. E tinha dias que não vinha nenhuma. E, dias que vinha uma, duas gestantes. (GA2P2).

\section{Práticas obstétricas e pediátricas e os desafios no puerpério (imediato e mediato)}

Os enfermeiros destacaram as dificuldades relacionadas à intervenção médica por meio da cesariana, uma vez que o município não dispõe de espaço/infraestrutura para acomodar e receber a mãe e o bebê após o nascimento. Nesse cenário, fica inviável a mãe oferecer o leite materno ao seu bebê, fragilizando o vínculo entre ambos e o processo efetivo de amamentação. As práticas realizadas pelo enfermeiro que atua na assistência à mulher durante o ciclo gravídico e puerperal necessitam fortalecer e incentivar o AM, promovendo ações humanizadas de cuidado ao binômio materno-infantil, independentemente da via de parto, seja por via vaginal ou cesariana, garantindo que a atuação dos profissionais ocorra por meio da adoção das melhores práticas, legitimadas em evidências científicas, como as recomendações oriundas da OMS, respeitando as particularidades e especificidades de cada mulher. 
A parte mais difícil é a gente fortalecer a questão bospitalar, da maternidade, do aleitamento, do incentivo, essa parte mais humanizada, acompanhei a cesárea da minha irmã aqui do município. Depois que o bebê nasceu foi feito a bigiene dele e ele voltou para a sala de recuperação e eu o coloquei no peito e começou aquele reflexo de sucção no peito, então é isso aí que falta. O que acontece, a mãe fica na sala de recuperação o bebê vai para o quarto com os familiares. (GA2P4).

A maioria das puérperas ganham seus filhos de parto cesárea, elas não passam pelo período de trabalbo de parto, a maioria agenda. Então, ela não tem a descida do leite, que não tem toda aquela curva hormonal, liberação de ocitocina. (GA2P3)

Durante o puerpério a mulher enfrenta inúmeros desafios para adaptar-se à nova vida. De acordo com os enfermeiros, foi observado que, repetidas vezes, após a alta hospitalar, as puérperas recebem precocemente a receita com a prescrição de leite industrializado. Esse procedimento propicia que as puérperas acabem associando que diante de qualquer situação adversa ela pode recorrer ao uso de mamadeira. A inserção de práticas protetoras e promotoras do AM é salutar para o crescimento e o desenvolvimento saudável do lactente, sem contar os benefícios maternos

\footnotetext{
O que eu tento fazer é qualificar consulta. Talvez, fazer um trabalbo com os pediatras no hospital também, que seria interessante. Porque eles já saem de lá com a fórmula e já está subentendido que na primeira dificuldade dá o leite industrializado. Isso dificulta bastante. Na verdade, o bebê nasce eles dão o copinho. É uma dificuldade que eu acho que atrapalha. Eu acho que os obstetras também poderiam influenciar mais também o aleitamento materno, porque é um processo. (GA2P7).
}

Foi destacado pelos enfermeiros do estudo que é requerido a necessidade de ofertar momentos para a capacitação multidisciplinar, envolvendo diversos profissionais com foco nas ações que promovam mais informação, segurança e qualidade assistencial durante o ciclo gravídico e puerperal.

\footnotetext{
Eu acho que qualificar todos os outros profissionais que acompanham, não só os enfermeiros e médicos que acompanham nas consultas de pré-natal, mas o agente comunitário de saúde na visita domiciliar, o técnico na bora da vacina, na bora do teste do pezinho, e principalmente uma conversa mais estreita com os pediatras que tem maior proximidade com a puérpera. (GA2P5).
}

Seria interessante as capacitações, assim da rede como um todo, porque a gente tem bastante capacitações aqui na área da assistência, mas os médicos eu acho que não tanto. Principalmente os ginecologistas, os pediatras e também esse cuidado intersetorial, do CRAS também falar um pouco mais sobre amamentação, talvez dar uma ênfase maior. (GA2P3).

\section{Discussão}

Após a análise dos dados, destacam-se que as práticas de enfermeiros da APS estão vinculadas com a educação em saúde, seja no início, no final da gestação ou no período do puerpério envolvendo a mulher e o lactente. Outra situação elencada com forte influência na adesão à amamentação é a construção de vínculo não apenas com a mulher, mas incluindo a sua rede de apoio (familiares, acompanhantes etc.). As influências socioculturais advêm principalmente do entendimento dos familiares com mais experiência, representados pela figura materna (mães e avós), que possuíam a crença de que o leite materno é fraco e, por isso, não atendia às necessidades do lactente, confirmado pelo choro do bebê.

Além disso, acrescenta-se as ações voltadas para o incentivo, a proteção e a promoção do AM ainda no puerpério imediato e mediato, especialmente no contexto hospitalar, evitando o uso precoce de leite industrializado e, por fim, a importância da inclusão de práticas que promovam a qualificação profissional com o foco na efetividade e eficácia do AM.

A prática da realização da consulta pré-natal desempenhada pelo enfermeiro, enfermeiro obstetra ou obstetriz da APS vem destacando a importância desses profissionais no âmbito da ESF. Um estudo apontou que mais da metade dos atendimentos clínicos, relacionados ao pré-natal de risco habitual, no Brasil, são realizados durante a consulta de enfermagem. Os aspectos que favorecem a atuação do enfermeiro na consulta e dão visibilidade à sua atuação estão associados à qualidade do exame físico, interesse/motivação do profissional, disponibilidade de tempo e o conhecimento teórico, técnico-científico. Essas características foram identificadas por gestantes que apontam como fator associado a qualidade no atendimento ${ }^{(4)}$.

É sobre essa perspectiva que os profissionais intervêm no processo da amamentação, à medida que promovem práticas de educação em 
saúde com o intuito de empoderamento da tomada de decisão, sob a perspectiva de escolha da gestante/puérpera. Entretanto, os obstáculos associados ao AM são diversos, mas, de maneira geral, as argumentações para seu abandono envolvem inúmeros mitos e desinformação, mesmo entre mulheres com nível socioeconômico mais elevado, o que potencializa e desafia os profissionais frente à necessidade de intervenções efetivas de apoio à nutriz ${ }^{(9)}$. Atrelado a isso, a inclusão de avós e dos pais das crianças nos processos educativos e decisórios sobre a amamentação é considerada como forte influência para a mulher na sua tomada de decisão em amamentar e/ou na manutenção desta prática. É nesse contexto que as evidências destacam que as práticas culturais possuem maior interferência na adesão à amamentação do que, muitas vezes, as orientações e recomendações dos profissionais da saúde $\mathrm{e}^{(10-12)}$.

A implementação das práticas de educação em saúde em prol da AM pode mitigar os desafios e as dificuldades em amamentar, especialmente às primíparas ou aquelas que experienciam a amamentação, que, muitas vezes, está associada aos sentimentos de insegurança, medo e ansiedade. Ainda, estes sentimentos favorecem os piores desfechos na amamentação, pois relacionam-se aos desgastes nos contextos físico, emocional e social, especialmente associados a mitos sociais (construídos pela própria família e/ou pessoas próximas), como leite fraco, volume insuficiente ou "baixo ganho de peso" do lactente ${ }^{(12)}$. É comum, nesse contexto, a interrupção ou o espaçamento da amamentação.

Um estudo sobre os conhecimentos, atitudes e práticas das avós relacionados ao aleitamento materno revelou que estas conhecem os benefícios da amamentação, a importância de uma dieta especial e hidratação adequada para a produção de leite de boa qualidade, porém relatam a necessidade de complementação do leite materno antes do sexto mês de vida. Em suma, o estudo evidenciou que as avós são figuras centrais no que refere ao apoio à amamentação, por meio da disseminação de seus conhecimentos, atitudes e práticas, conferindo suporte às suas filhas e noras para amamentarem e também contribuem para o desinteresse por parte da nutriz em amamentar devido a opiniões contrárias e orientações inadequadas ${ }^{(13-14)}$.

Estudos sobre os fatores associados à adesão ao aleitamento materno exclusivo identificaram que as orientações sobre a amamentação durante o pré-natal não apresentam benefícios diretos em relação à adesão e eficácia ${ }^{(14-15)}$. Em contrapartida, outro estudo destaca o importante papel do aconselhamento gestacional, pois, além de propiciar o aumento da autoeficácia da amamentação das mães, amplia a resolutividade dos problemas e dificuldades durante o período ${ }^{(3)}$. É nesse contexto que os profissionais de Enfermagem, em especial o enfermeiro, necessitam propiciar um ambiente tranquilo, seguro e confortável para a gestante, fornecendo informações adequadas sobre a gravidez e a amamentação, a fim de mitigar os impactos e fatores que podem gerar os sentimentos negativos, as dúvidas, os anseios e a insegurança que emergem com base na sensibilidade, empatia e afetividade ${ }^{(8-9)}$.

Os fatores sociais, culturais, econômicos e ambientais influenciam no aleitamento materno no que tange ao início e à duração incluindo o desmame ${ }^{(15-16)}$. O início precoce da amamentação, também influenciado por fatores sociais, além de estimular o bebê a sugar de maneira eficaz, recebendo assim o colostro, que é a primeira imunização do lactente, auxilia a mãe na expulsão da placenta, na proteção da criança e na saúde da mãe. Além disso, economicamente, reduz os custos na política de saúde pública global e também no Sistema Único de Saúde (SUS), com a redução do número de consultas, internações e medicações, não sobrecarregando o sistema de saúde ${ }^{(17-18)}$.

Estudos sobre a promoção do aleitamento materno no pré-natal revelou que somente em $50 \%$ das consultas de enfermagem foram realizadas as orientações voltadas ao aleitamento materno ${ }^{(14-15)}$, e que, em sua maioria, estavam relacionadas ao preparo das mamas, vantagens e importância do aleitamento materno exclusivo para a mãe e o $\mathrm{RN}^{(14,18-19)}$. Considera-se que essas informações não são suficientes, pois aspectos 
sobre dificuldades de manejo/pega do neonato, complicações e demora da apojadura não foram mencionadas nas práticas educativas, seja no grupo ou na consulta de enfermagem durante o acompanhamento no pré-natal ${ }^{(8,18-19)}$.

No que tange aos grupos de gestantes, os enfermeiros reconhecem a importância e o caracterizam como ferramenta imprescindível e dinâmica para educação e promoção em saúde. O grupo de gestantes, sob uma perspectiva de discussão coletiva, busca promover a troca de vivências e fortalecer o empoderamento das mulheres no processo de parto e do nascimento, aumentando a autonomia das suas escolhas em relação a possíveis intervenções e mudar a forma de nascer ${ }^{(15-20)}$. Os participantes do presente estudo afirmaram que enfrentam dificuldades para a adesão das gestantes aos grupos, mesmo entrave encontrado por autores em práticas grupais de educação em saúde ${ }^{(16-21)}$.

Os grupos de gestantes são considerados pelos enfermeiros como uma estratégia oportuna para propiciar momentos de educação em saúde que favorecem o empoderamento materno para a escolha e a decisão em amamentar ${ }^{(8)}$. No entanto, os profissionais encontram dificuldade na adesão à participação no grupo, seja por aspectos culturais (as gestante pensam que nas consultas é possível solucionar as dúvidas e receber as orientações), ou pela dificuldade de participar dos encontros, pois as atividades laborais não permitem, dentre outras causas. Nessa perspectiva, destaca-se que a oferta de um grupo de gestante durante o pré-natal configura-se como salutar ferramenta de acolhimento e fortalecimento do vínculo diante de um período singular, de especial significado, muitas vezes extremamente aguardado pela mulher e sua família, carregado de sentimentos e expectativas para viver a experiência única de ser mãe ${ }^{(4,8)}$.

Estudos internacionais destacam que práticas e estratégias educacionais puerperais sistematizadas foram eficazes na manutenção do aleitamento materno exclusivo até os seis meses de vida. Na comparação com o grupo que recebeu as informações, o grupo que não recebeu as orientações regulares teve três vezes mais chance de abandono do aleitamento materno ${ }^{(21-22)}$. Essa discussão reforça a necessidade da presença da atuação do enfermeiro na assistência ao ciclo gravídico da mulher, extensivo à etapa de puerpério e da puericultura, promovendo práticas reflexivas, seguras, protetivas, promotoras e incentivadoras à amamentação ${ }^{(17-18)}$.

Nas últimas décadas, os avanços técnico-científicos relacionados à assistência de saúde à mulher durante o ciclo gravídico puerperal vêm mudando o cenário da parturição que outrora era realizado em domicílio e hoje concentra boa parte dos nascimentos no ambiente hospitalar, principalmente por meio da realização de cesarianas agendadas ${ }^{(6)}$. O mais importante, independentemente do local em que o trabalho de parto, parto e nascimento ocorra, seja no domicílio ou no contexto hospitalar, é que a autonomia e o respeito às crenças, a cultura e a individualidade sejam contemplados pelos profissionais envolvidos no processo de parturição, impulsionando o protagonismo da mulher, subsidiado por práticas humanizadas e seguras ao binômio materno-infantil ${ }^{(6,20)}$.

Muitas vezes, a realização de um parto via cesárea pode representar entrave e inviabilizar o início da amamentação logo na primeira hora de vida, haja vista a necessidade de assistência pós-operatória que interfere e amplia o tempo para o primeiro contato entre mãe e filho. Entretanto, as rotinas de puerpério imediato possuem relação com a melhora da adesão, e práticas como aleitamento na primeira hora e o alojamento conjunto favorecem a manutenção do aleitamento materno $^{(24)}$. Desse modo, o conhecimento prévio dos fatores associados à interrupção do aleitamento materno exclusivo no puerpério decorrentes do tipo de parto pode facilitar o planejamento de ações e políticas locais para melhorar os índices de desmame precoce, visando diminuir a morbimortalidade infantil ${ }^{(23-24)}$.

A amamentação perante a sociedade é compreendida como um ato natural, que proporciona o primeiro contato afetivo e uma série de vantagens tanto para a mãe quanto para o lactente, o que também está correto em relação ao laço afetivo; porém não é um processo natural e 
bonito como relatado para todas as mães, pois podem ocorrer várias complicações durante a amamentação e consequentemente o desmame precoce $^{(25)}$. Por isso, também é salutar incluir a rede de apoio da gestante, incluindo a família e suas distintas formas de constituição desde o início das consultas de pré-natal, repassando as orientações e fortalecendo a importância do aleitamento materno para a mulher e a criança. A rede de apoio pode contribuir efetivamente em prol da manutenção da prática materna da amamentação ${ }^{(24)}$.

Ressalta-se que a oferta de grupos voltados para a educação em saúde da gestante e do lactente possam incluir as famílias e/ou companheiro(a), uma vez que é notório a importância e a influência desses atores. Ainda, o enfermeiro pode disponibilizar outras estratégias para empoderar a mulher para a oferta do leite materno, como, por exemplo, organizar parcerias com outros profissionais de saúde a fim de ampliar o escopo de conhecimento e a troca de informações e orientações em prol da manutenção do aleitamento materno, buscando desmistificar as questões socioculturais de outrora que, muitas vezes, inviabilizam a prática.

Entende-se como limitação do estudo a descrição local, sob saberes de grupo de enfermeiros da APS em um contexto social e demográfico específico/regional. O estudo não permite generalizações, porém, enfatiza aspectos que possam servir de reflexão e aproximação em outros cenários semelhantes. Recomenda-se a realização de estudos que proponham práticas interventoras de educação em saúde para adesão à amamentação e possibilitem a sua utilização como uma prática de cuidado dos enfermeiros, devidamente testadas e validadas.

\section{Conclusão}

As práticas de enfermeiros apontam para a importância da implementação de ações de educação em saúde, construção de vínculo, oferta de grupos de gestantes e organização de capacitação multiprofissional, a fim de fortalecer e empoderar a mulher em todo o ciclo gravídico-puerperal com vistas a mitigar as práticas e as influências socioculturais que desfavorecem o início e a manutenção do AM.

Os enfermeiros da atenção primária em saúde reconhecem os benefícios e a importância do aleitamento materno para a mãe e a criança. Entendem que suas orientações e incentivos devem acontecer durante o pré-natal, com recomendações no início do pré-natal e reforçadas no terceiro trimestre e puerpério. Outro cenário, considerado essencial para a adesão, é o obstétrico hospitalar (pós-parto imediato), no qual, o incentivo precoce e a minimização da utilização das fórmulas lácteas, precoces, favorecem a maior adesão à amamentação. As práticas culturais são influências fortes nos processos decisivos em amamentar, em especial o aleitamento materno exclusivo, e requerem a insistência e a necessidade de empoderamento das mães e das famílias sobre a melhor prática e a desconstrução de conceitos "mitológicos" que recaem sobre o ato de amamentar.

\section{Colaborações:}

1 - concepção, projeto, análise e interpretação dos dados: Giovana Callegaro Higashi e Sibeli Seefeld dos Santos;

2 - redação do artigo e revisão crítica relevante do conteúdo intelectual: Giovana Callegaro Higashi, Rosielle Souza da Silva, Leonardo Bigolin Jantsch, Rafael Marcelo Soder e Luiz Anildo Anacleto da Silva;

3 - aprovação final da versão a ser publicada: Giovana Callegaro Higashi, Rosielle Souza da Silva e Leonardo Bigolin Jantsch.

\section{Referências}

1. Boccolini CS, BoccoliniI PMM, Monteiro FR, Venâncio SI, Giugliani ERJ. Tendência de indicadores do aleitamento materno no Brasil em três décadas. Rev Saúde Pública. 2017 nov;51:108. DOI: http://dx.doi.org/10.11606/ s1518-8787.2017051000029

2. Victora CG, Bahl R, Barros AJ, França GV, Horton S, Krasevec J, et al. Breastfeeding in the 21st century: epidemiology, mechanisms, and lifelong 
effect. Lancet. 2016 Jan;387(10017):475-90. DOI: https://doi.org/10.1016/S0140-6736(15)01024-7

3. Almeida RSS, Reticena KO, Gomes MFP, Fracolli LA. Vivências de puérperas frente à atuação da equipe de enfermagem durante o trabalho de parto. Rev Pesqui (Univ F Estado Rio J Online) [Internet]. 2020 jan-dez [cited 2020 Jun 12];12:350-4. Available from: https://pesquisa. bvsalud.org/portal/resource/pt/biblio-1051360

4. Shafaei FS, Mirghafourvand M, Havizari S. The effect of prenatal counseling on breastfeedinf self-efficacy and frequency of breastfeeding problems in mothers with previous unsuccessful breastfeeding: a randomized controlled clinical trial. BMC Womens Health. 2020;20(1):94. DOI: 10.1186/s12905-020-00947-1

5. Gomes CBA, Dias RS, Silva WGB, Pacheco MAB, Sousa FGM, Loyola CMD. Consulta de enfermagem no pré-natal: narrativas de gestantes e enfermeiras. Texto contexto - enferm. 2019;28:e20170544. DOI: https://doi.org/10.1590/ 1980-265x-tce-2017-0544

6. Pereira RM, Alves VH, Rodrigues DP, Branco MBLR, Lopes FO. O conhecimento do enfermeiro acerca do manejo clínico da amamentação: saberes e práticas. Rev pesqui cuid fundam [Internet]. 2019 [cited 2020 May 13];11(1):80-7. Available from: http://ciberindex. $\mathrm{com} / \mathrm{c} / \mathrm{ps} / \mathrm{P} 111080$

7. Charmaz K. A construção da teoria fundamentada: guia prático para análise qualitativa. Porto Alegre: Artmed; 2009.

8. Alves TCM, Coelho ASF, Sousa MC, Cesar NF, Silva PS, Pacheco LR. Contribuições da Enfermagem obstétrica para as boas práticas no trabalho de parto e parto vaginal. Enferm foco [Internet]. 2019 [cited 2020 May 23];10(4):54-60. Available from: https://pesquisa.bvsalud.org/ portal/resource/pt/biblio-1052473

9. Souza EFC, Fernandes RAQ. Autoeficácia na amamentação: um estudo de coorte. Acta paul enferm. 2014;27(5):465-70. DOI: https://doi. org/10.1590/1982-0194201400076

10. Castro IR, Melo MCP, Morais RJL, Santos ADB. Partejar de primíparas: reflexos na amamentação. Rev enferm UERJ. 2019;27:e43354. DOI: http:// dx.doi.org/10.12957/reuerj.2019.43354

11. Thuler ACMC, Wall ML, Souza MAR. Caracterização das mulheres no ciclo gravídico-puerperal e o incentivo à amamentação precoce. Rev enferm
UERJ. 2018;26:e16936. DOI: http://dx.doi.org/ 10.12957/reuerj.2018.16936

12. Benedett A, Ferraz L, Silva IA. Breastfeeding: a search for comfort. Rev Fund Care Online. 2018;10(2):458-64. DOI: http://dx.doi.org/10.9789/ 2175-5361.2018.v10i2.458-464

13. Angelo BHB, Pontes CM, Sette GCS, Leal LP. Knowledge, attitudes and practice of grandmothers related to breastfeeding: a meta-synthesis. Rev Latino-Am Enfermagem. 2020;28:e3214. DOI: https://doi.org/10.1590/15188345.3097 .3214

14. Ferreira HLOC, Oliveira MF, Bernardo EBR, Almeida PC, Aquino OS, Pinheiro AKB. Fatores Associados à Adesão ao Aleitamento Materno Exclusivo. Ciênc saúde coletiva. 2018;23(3):683-90. DOI: 10.1590/1413-81232018233. 06262016

15. Rocha PA, Friedrich DBC, Horta NC, Souza MD. Grupos educativos desenvolvidos por enfermeiros na Atenção Primária à Saúde. Enfermeria Comunitaria [Internet]. 2019 [cited 2020 Jun 2];15. Available from: http://ciberindex.com/ index.php/ec/article/view/e11077

16. Palhoni ARG, Souza MCMR, Lima MAO, Soares NP. Adesão de gestantes a atividade educativa em uma Unidade Básica de saúde de Belo Horizonte MG. Enf rev [Internet]. 2017 [cited 2020 Jun 5];20(1):55-60. Available from: http://periodicos.pucminas.br/index.php/ enfermagemrevista/article/view/15415

17. Wang S, Liu J, Guo N, Jiang H. The relationship between birthing related factors and maternal breastfeeding confidence in China. Women Birth. 2020 Feb;(19):31022-4. DOI: https://doi. org/10.1016/j.wombi.2020.02.014

18. Silva DD, Scmitt IM, Costa R, Zampieri MFM, Bohn IE, Lima MM. Promoção do aleitamento materno no pré-natal: discurso das gestantes e dos profissionais de saúde. REME rev min enferm. 2018;22:e1103. DOI: http://www.dx.doi. org/10.5935/1415-2762.20180031

19. Guimarães DC, Lima BN, Menezes ASS, Gomes CM, Borges PV, Gomes NT, et al. Conhecimento da puérpera sobre amamentação na Atenção Básica. Rev Eletrônica Acervo Saúde. 2018;(18):e107. DOI: https://doi.org/10.25248/ reas.e107.2019

20. Hanzen IP, Zanotelli SS, Zanatta EA. Diagnósticos, intervenções e resultados de 
Enfermagem para subsidiar a consulta de Enfermagem à criança. Enferm foco [Internet]. 2019 [cited 2020 Jul 10];10(7):16-21. Available from: https://pesquisa.bvsalud.org/portal/resource/pt/ biblio-1050579

21. Zirr GM, Gregório VRP, Lima MM, Collaço VS. Autonomia da mulher no trabalho de parto: contribuições de um grupo de gestantes. REME rev min enferm [Internet]. 2019 [cited 2020 Jul 20];23:e1205. Available from: https://pesquisa. bvsalud.org/portal/resource/pt/biblio-1051589

22. Fassarella BPA, Maleck M, Ribeiro WA, Pimenta ESS, Corrêia MCB, Pinheiro DS, et al. Percepção da equipe de enfermagem frente ao aleitamento materno: do conhecimento à implementação. Nursing [Internet]. 2018 [cited 2020 Jul 14];21(247):2489-93. Available from: http://www.revistanursing.com.br/revistas/247/ pg43.pdf

23. Kuswara K, Knigth T, Campbell KJ, Hesketh KD, Zheng M, Bolton KA, et al. Breastfeeding and emerging motherhood identity: An interpretative phenomelogical analysis of first time Chinese Autralian mothers' breastfeeding experiences. Women Birth. 2020 Mar 20;S1871-5192(19)30940. DOI: https://doi.org/10.1016/j.wombi.2020.03.005

24. Vieira FS, Costa ES, Sousa GC, Oliveira TMP, Neiva MJLM. Childbirth Influence Towards the During Puerperium Period. Rev Fund Care Online. 2019;11(2):425-31. DOI:10.9789/2175-531.2019. v11i2.425-431

25. Antoñanzas-Baztán E, Belintxon $\mathrm{M}$, Marín-Fernández B, Redín-Areta MD, Mujika A, Pumar-Méndez MJ, et al. Six-month breastfeeding maintenance after a self-efficacy promoting programme: a exploratory trial. Scand J Caring Sci. 2020 May 12;(9). DOI: https://doi. org $/ 10.1111 /$ scs. 12870

Recebido: 26 de agosto de 2020 Aprovado: 3 de novembro de 2020

Publicado: 8 de fevereiro de 2021

A Revista Baiana de Enfermagem utiliza a Licença Creative Commons - Atribuição-NãoComercial 4.0 Internacional. https://creativecommons.org/licenses/by-nc/4.0/ Este artigo é de acesso aberto distribuído sob os termos da Licença Creative Commons (CC BY-NC). Esta licença permite que outros remixem, adaptem e criem a partir do seu trabalho para fins não comerciais. Embora os novos trabalhos tenham de lhe atribuir o devido crédito e não possam ser usados para fins comerciais, os usuários não têm de licenciar esses trabalhos derivados sob os mesmos termos. 